\title{
Study on Seasonal Variation Characteristics of Salinity Distribution in the Bohai Sea and its Influential Factors Based on the High Resolution FVCOM
}

\author{
Zhao Chen Yao ${ }^{1, a}$, Wen Ling Liü, \\ ${ }^{1}$ Tianjin Key Laboratory of Marine Resources and Chemistry, College of Marine Science and Engin \\ eering, Tianjin University of Science and Technology, Tianjin 300457, China \\ am18622301876@163.com \\ b Iwl@tust.edu.cn
}

Keywords: High Resolution; FVCOM; Bohai Sea; Salinity

\begin{abstract}
In this paper, salinity field is numerically simulated by using unstructured grid FVCOM (finite volume coastal ocean model) to analyze the seasonal characteristics of salinity in Bohai Sea and the influence of Yellow River runoff and precipitation on salinity is also studied through sensitivity experiment. The results show that the vertical distribution of salinity in Bohai Sea is homogeneous and seasonal characteristics of salinity are that it increases in winter and gradually decreases from autumn to summer, but increases again in autumn and gradually restores to the winter level. The Yellow River runoff and precipitation can find their influence mainly in summer and autumn. The influence of Yellow River runoff concentrates in the area nearby Laizhou Bay, which results in change rate of salinity up to $20 \%$, while the influence of precipitation sweeps through almost the entire Bohai Sea, which makes the change rate of salinity reach its maximum for the whole year in summer, that is $9 \%$ for Bohai Gulf, $7 \%$ for Liaodong Gulf and $6 \%$ for Laizhou Bay.
\end{abstract}

\section{Introduction}

In recent decades, with the change of climate and river and other conditions of Bohai Sea areas, the salinity in Bohai Sea has undergone tremendous change that is the average salinity in Bohai Sea increased nearly 2.0PSU ${ }^{[1]}$. The salinity characteristics of Bohai Sea have changed, thereby causing great changes of ecological environment of Bohai Sea and degradation and even extinction of many important biological resources. For example, prawn, little yellow croaker, hairtail and other biological resources of the Yellow River entrance and Laizhou Bay are in serious degradation and on verge of extinction ${ }^{[2]}$. Thus it can be seen that study on the seasonal characteristics of salinity in Bohai Sea and its influential factors plays a significant role in helping us understand the changes of environmental elements. This is not only the needs of scientific development but also one of the key factors to the sustainable development of Bohai Sea ${ }^{[3]}$.

With the improving of calculating ability, ocean model is applied to marine scientific research more and more widely. By using POM (Princeton Ocean Model), Xu Jiangling ${ }^{[4]}$ found that the vapor flux contributes most to the inter-annual variation of salinity in Bohai Sea, and the water exchange with the Yellow Sea also has some certain influence on it, but the Yellow River does little to it. Influential factors of salinity in Laizhou Bay have been studied by Zhao Peng et al. ${ }^{[5]}$ through a box model and it is concluded that the monthly average salinity in Laizhou Bay varies with seasons, which is influenced by the Yellow River runoff and net evaporation. Average salinity in the bay, however, is determined primarily by the Yellow River runoff and has a faster response to the Yellow River runoff than to net evaporation. By using HAMSOM, Mao Xinyan et al. ${ }^{[6]}$ believe that salinity change in Laizhou Bay is mainly influenced by the Yellow River runoff, while salinity change of other sea areas in Bohai Sea is affected by the intrusion of high-salinity water in the corresponding rivers and North Yellow Sea. But some problems still exist in these researches, such as low resolution of time and space of model accuracy and forcing data used for driving the model. Hainbucher et al. ${ }^{[7]}$ used HAMSON and came to a conclusion that adoption of boundary condition, 
low resolution of initial data and climatologically average forcing data has an influence on the accuracy of stimulation results, which results insufficient description of salinity change of Bohai Sea. So, based on the high resolution FVCOM, this paper selected the forcing data with high temporal and spatial resolution in 1993 as the drive to stimulate the change process of hydrodynamic force and salinity in Bohai Sea. This paper focuses on analyzing the seasonal characteristics of salinity and meanwhile makes a research into the influence of various factors on salinity in Bohai Sea by designing corresponding sensitivity experiment.

\section{Model Configuration and Sensitivity Experiment}

The calculation region in this paper is $37^{\circ} 07^{\prime} \sim 41^{\circ}$ and $117^{\circ} 35^{\prime} \sim 125^{\circ} 10^{\prime} \mathrm{E}$ and triangular gird is adopted in horizontal direction. Resolution ratio of all other position is about $0.05^{\circ}$ except that the resolution ratio of the grid near the boundary is about $0.1^{\circ} . \sigma$ coordinate system is adopted in vertical direction, which is equally divided into eleven levels. The time step of external mode is about 10 seconds and the external to internal model ratio is 5:1. Charted depth in the model is obtained by the $1^{\prime} \times 1^{\prime}$ interpolation of charted depth of the East China Sea into the grids that is mentioned by Choi et al. ${ }^{[8]}$, while coastline information is the high resolution data, which is obtained through satellite retrieval. Surface forcing adopts the data of ERA-interim, whose time resolution is $6 \mathrm{~h}$ and spatial resolution is $0.25^{\circ}$. The data of wind field in Bohai Sea, the Yellow Sea and the East China Sea can be summarized as high-resolution sea surface wind field $10 \mathrm{mU}$ and V for wind speed ${ }^{[9]}$, time resolution is 3 , spatial resolution is $0.1^{\circ}$. By adopting OTPS(OSU tidal prediction software), model open boundary drives based on the real time water level of eight primary tidal predication, which is $\mathrm{M} 2, \mathrm{~S} 2, \mathrm{~N} 2, \mathrm{~K} 2, \mathrm{~K} 1, \mathrm{O} 1, \mathrm{P} 1$ and Q1. The temperature and salinity data in open boundary adopt the data of NEMO2.3 (nucleus of European modeling of the ocean) ${ }^{[10]}$. Initial conditions of temperature and salinity adopt data of WOA09 (world ocean atlas 2009). Initial values of water level and current velocity are respectively set up as 0 . The influence of four main rivers into Bohai Sea every month, which is the Yellow River, Haihe River, Luanhe River and Liaohe River, is also taken into consideration ${ }^{[11,12] .}$

Considering that salinity characteristics are influenced by various factors, this paper conducts sensitivity experiment by taking precipitation and rivers' runoff into consideration to study their influence on the salinity. It should be noted that annual runoff of the Yellow River is much larger than the annual runoff of other rivers. This is the reason that the Yellow River runoff is selected as the representative to be studies in this paper. All the factors, which should be taken into consideration in the design of reference experiment and sensitivity experiment, are listed in Table 1. Reference experiment corresponds to the normal situation described in 1.1. Compared with reference experiment, experiment 1 doesn't take the Yellow River runoff into consideration, while experiment 2 doesn't take the precipitation into consideration.

Table 1 Design of Reference Experiment and Sensitivity Experiment

\begin{tabular}{|c|c|c|}
\hline Experiment & $\begin{array}{c}\text { Taking the Yellow River runoff } \\
\text { into consideration }\end{array}$ & $\begin{array}{c}\text { Taking precipitation into } \\
\text { consideration }\end{array}$ \\
\hline Reference experiment & Yes & Yes \\
\hline Experiment 1 & No & Yes \\
\hline Experiment 2 & Yes & No \\
\hline
\end{tabular}

\section{Model Verification}

Take the aerial survey data for the cross section at central Bohai Sea from the North Sea Branch of the State Oceanology Administration dated Feb. of 1993 to verify the reference experimental result, the data include the temperature and salinity of the cross section, and the location of the cross section was as shown in Figure 1. 


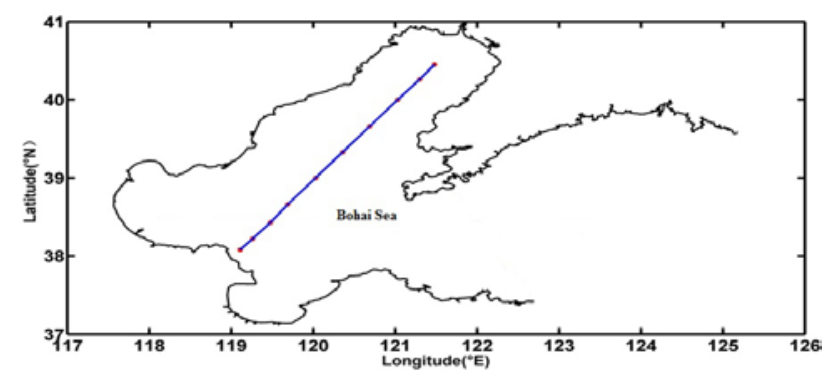

Figure 1 Cross Section Setup Diagram
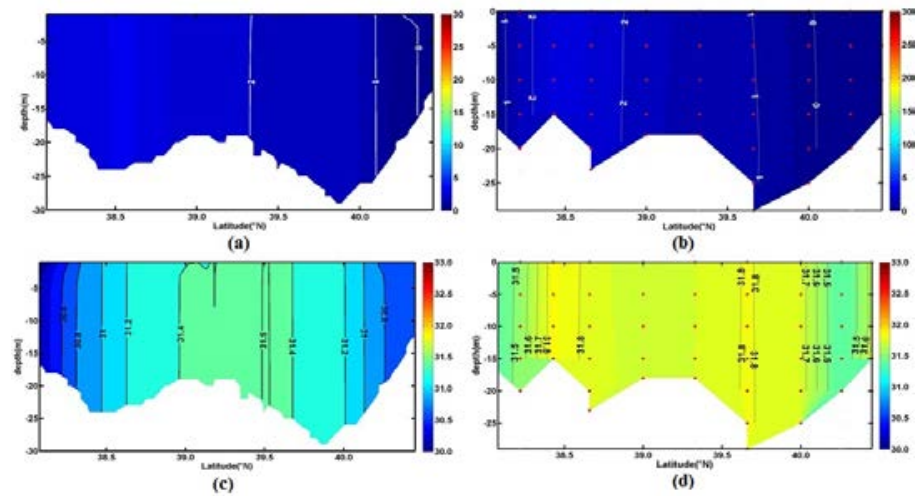

Figure 2 Distribution of Temperature and Salinity at the Cross Section of Central Bohai Sea ((a) and (c) are FVCOM results, and (b) and (d) are measured values)

It can be seen from Figure 2 that the analog value and measured value of temperature and salinity at the cross section of central Bohai Sea are fairly similar; therefore, it indicates that FVCOM model can well reflect the temperature and salinity characteristics of Bohai Sea.

\section{Salinity Characteristics of Bohai Sea}

\section{Seasonal Variation in High Surface Salinity of Bohai Sea.}

What is shown in Figure 3 is the distribution of salinity at surface and bottom layers of Bohai Sea in winter (with Feb. as the representative). High salinity water tongue stretched to central Bohai from Bohai Straight, and the salinity was 31.5PSU nearby Bohai Straight; the salinity of Liaodong Bay was similar to that of Bohai Bay, which were both around 30.5 31PSU; the salinity was minimum at Laizhou Bay and the salinity gradient was rather large, the salinity was around 29PSU nearby the bay mouth, and the salinity quickly decreased to below 28PSU toward inside of the bays.
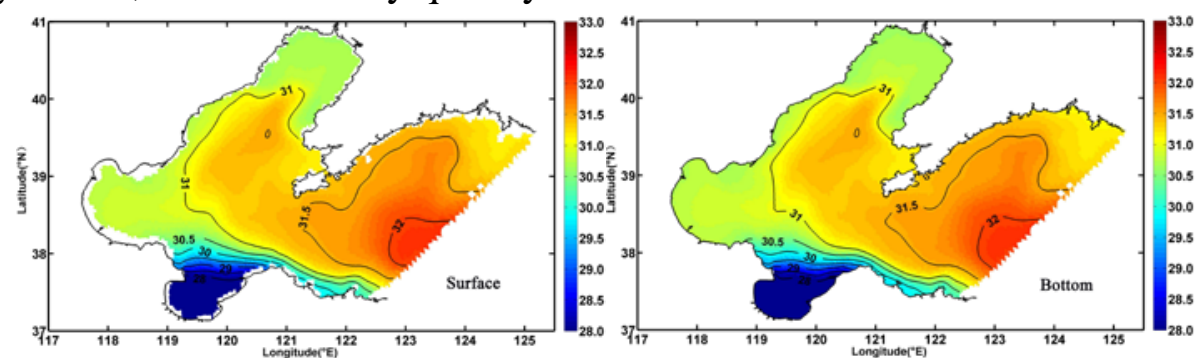

Figure 3 Salinity Distribution at the Surface and Bottom Layers of Bohai Sea in Feb.

What is shown in Figure 4 is the salinity distribution at the surface and bottom layers of Bohai Sea in spring (with May as the representative). Affected by the increase in the runoff of Liaohe River, a low salinity area appeared nearby the Liaohe River mouth. The salinity of Laizhou Bay increased by about 1 2PSU than that in winter, and the value was around 29 30PSU; meanwhile, the salinity gradient also decreased. 

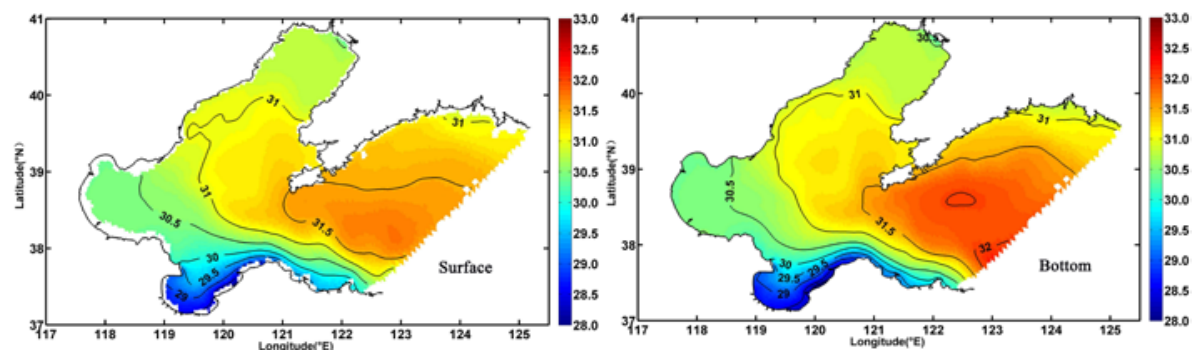

Figure 4 Distribution of Salinity at the Surface and Bottom Layers of Bohai Sea in May

What is shown in Figure 5 is the salinity distribution at the surface and bottom layers of Bohai Sea in summer (with Aug. as the representative). The increase in precipitation and river runoff further decreased the salinity of Bohai Sea; the salinity was around 30.5PSU in central Bohai Sea, the salinity was around 30PSU at the mouths of Liaodong Bay, Bohai Bay and Laizhou Bay, and it was all less than 30PSU inside the bays with the minimum at Laizhou Bay. Meanwhile, low salinity areas appeared at all the four river mouths; for instance, the salinity was less than 28.5 nearby the Liaohe River mouth, less than 30PSU nearby Luanhe River mouth, less than 29.5 nearby Haihe River mouth, and less than 30PSU nearby the Yellow River mouth.
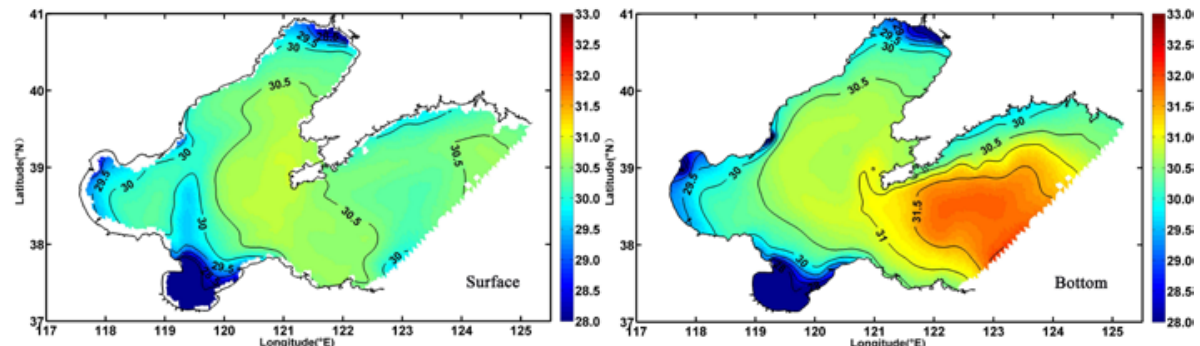

Figure 5 Salinity Distribution at the Surface and Bottom Layers of Bohai Sea in Aug.

What is shown in Figure 6 is the salinity distribution at the surface and bottom layers of Bohai Sea in fall (with Nov. as the representative). The decrease in precipitation and river runoff rendered the salinity for the most of Bohai Sea to start to increase as opposed to that of summer. The salinity exceeded 31PSU in central Bohai Sea, the salinity increased to over 30.5PSU at Liaodong Bay and Bohai Bay.
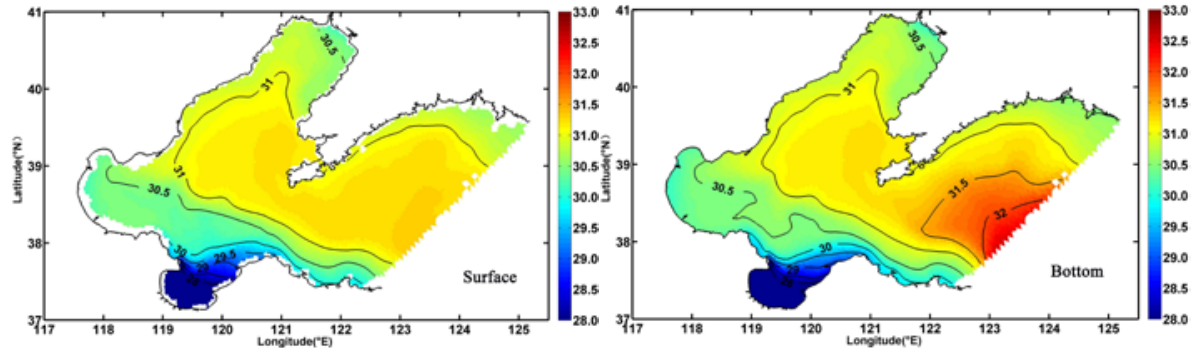

Figure 6 Salinity Distribution at the Surface and Bottom Layers of Bohai Sea in Nov.

\section{Seasonal Variation in Salinity at the Cross Section of Central Bohai Sea.}

What is shown in Figure 7 is the salinity distribution by month in 1993 at the cross section of the central Bohai Sea. In winter, the salinity values at both ends of the cross section were less than 30.5PSU, and the salinity was around 31.5PSU in central area. Since May, as the precipitation and river runoff increased, the salinity of the sea area started to decrease, and reached to minimum salinity of the year in Aug. with the salinity being around 30.8PSU at the central cross section, and the salinity was less than 30PSU at both ends. Meanwhile, vertical thermocline phenomenon developed gradually and reached the peak by July. Then, the thermocline disappeared gradually, the vertical mix was even, and the salinity gradually returned to the status of winter. 


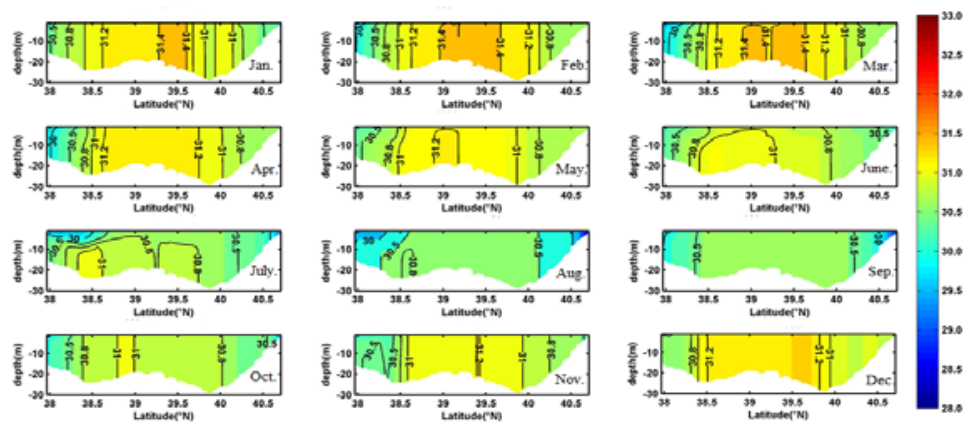

Figure 7 Salinity Distribution at the Cross Section of Central Bohai Sea from Jan. to Dec.

\section{Influence of the Yellow River Runoff and Precipitation on the Salinity of Bohai Sea}

\section{Influence of the Yellow River Runoff on the Salinity of Bohai Sea.}

What was given in Figure 8 is the salinity variance ratio compared between experiment 1 and the reference experiment in Feb., May, Aug. and Nov. The variance in salinity was small in Feb. and May with the maximum value only being $2 \%$; whereas the variance was significant in Aug. and Nov. while mainly concentrating nearby Laizhou Bay. As shown in figure 8, the maximum salinity variance ratio at the surface and bottom layers in Aug. appeared nearby the Yellow River mouth as being around 20\%, which decreased progressively from the river mouth to the outside, and the variance ratio decreased to $5 \%$ nearby the Laizhou Bay mouth. In Nov., the maximum salinity variance ratio at Laizhou Bay was around 15\%, but the distribution was different from that of Aug., the maximum salinity variance ratio was at the bottom of Laizhou Bay, and gradually decreased to $5 \%$ approx. from the bottom of the bay to the bay mouth.
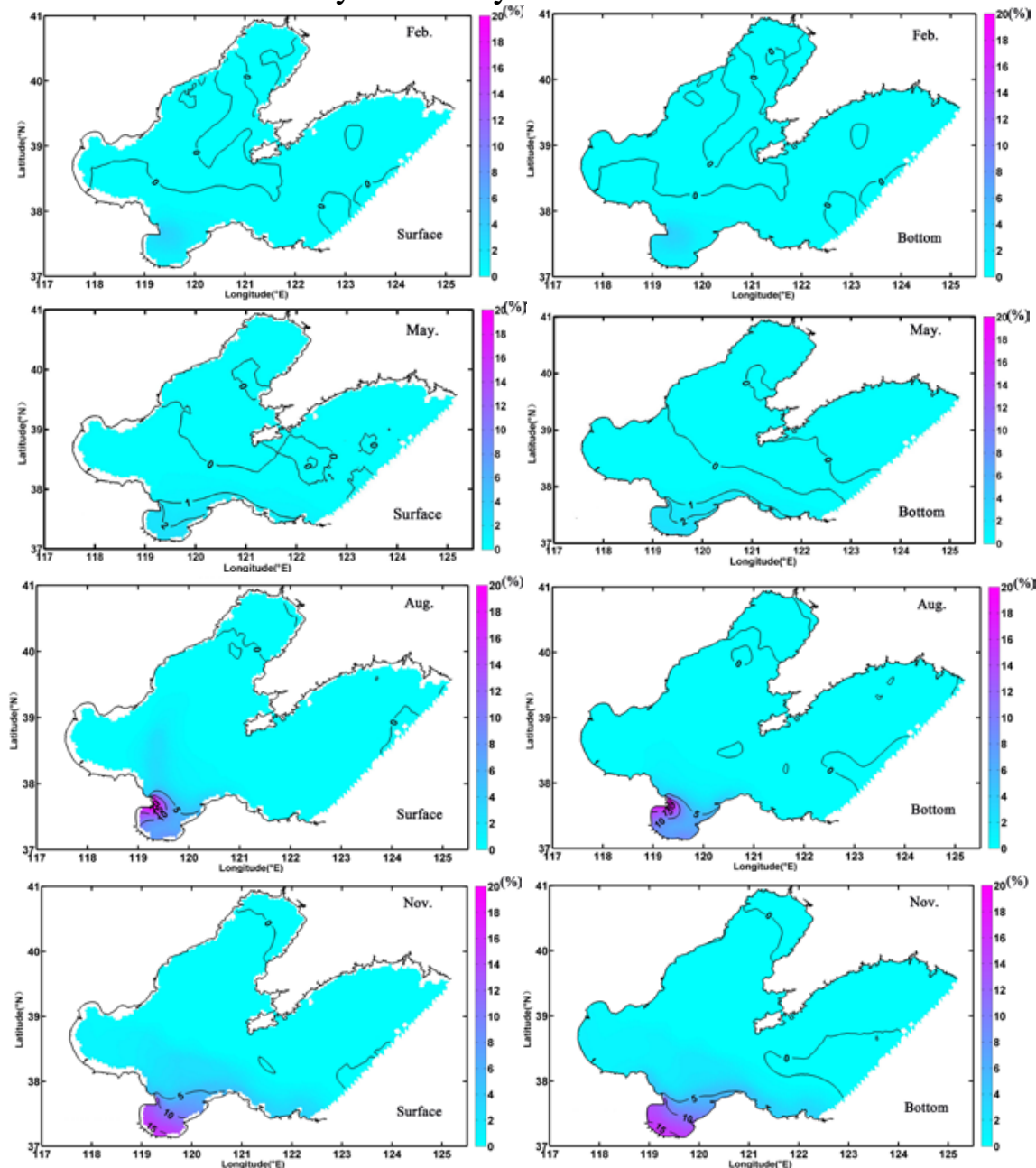

Figure 8 Salinity Variance Ratio at the Surface and Bottom Layers of Bohai Sea in the 4 Representative Months between Experiment 1 and the Reference Experiment 


\section{Influence of Precipitation on the Salinity of Bohai Sea.}

What was given in Figure 9 is the salinity variance ratio between experiment 2 and the reference experiment in Feb., May, Aug. and Nov. As the actual precipitation was fairly low in Feb., the maximum salinity variance ratio at the whole Bohai Sea area was only $0.2 \%$ as opposed to that without considering the precipitation conditions. In May, the variance ratio at the whole Bohai Sea area increased slightly as opposed to that without considering the precipitation conditions. While the increase in precipitation in Aug. rendered fairly significant variance ratio as opposed to that without considering the precipitation conditions. Although the influence of precipitation on the maximum salinity of Bohai sea was not as significant as the Yellow River runoff, the areas obviously affected by the precipitation was distributed in the whole Bohai Sea; among which, the variance ratio at Bohai Bay was 4\% 9\%, it was 4\% 7\% at Liaodong Bay, 4\% 6\% at Laizhou Bay, and 3\% 4\% at central Bohai Sea. As opposed to Aug., the salinity variance ratio decreased in Nov. at the whole Bohai Sea area, the main variance took place at Bohai Bay and Liaodong Bay, and the maximum variance ratio respectively decreased to $6 \%$ and $5 \%$ from $9 \%$ and $7 \%$.
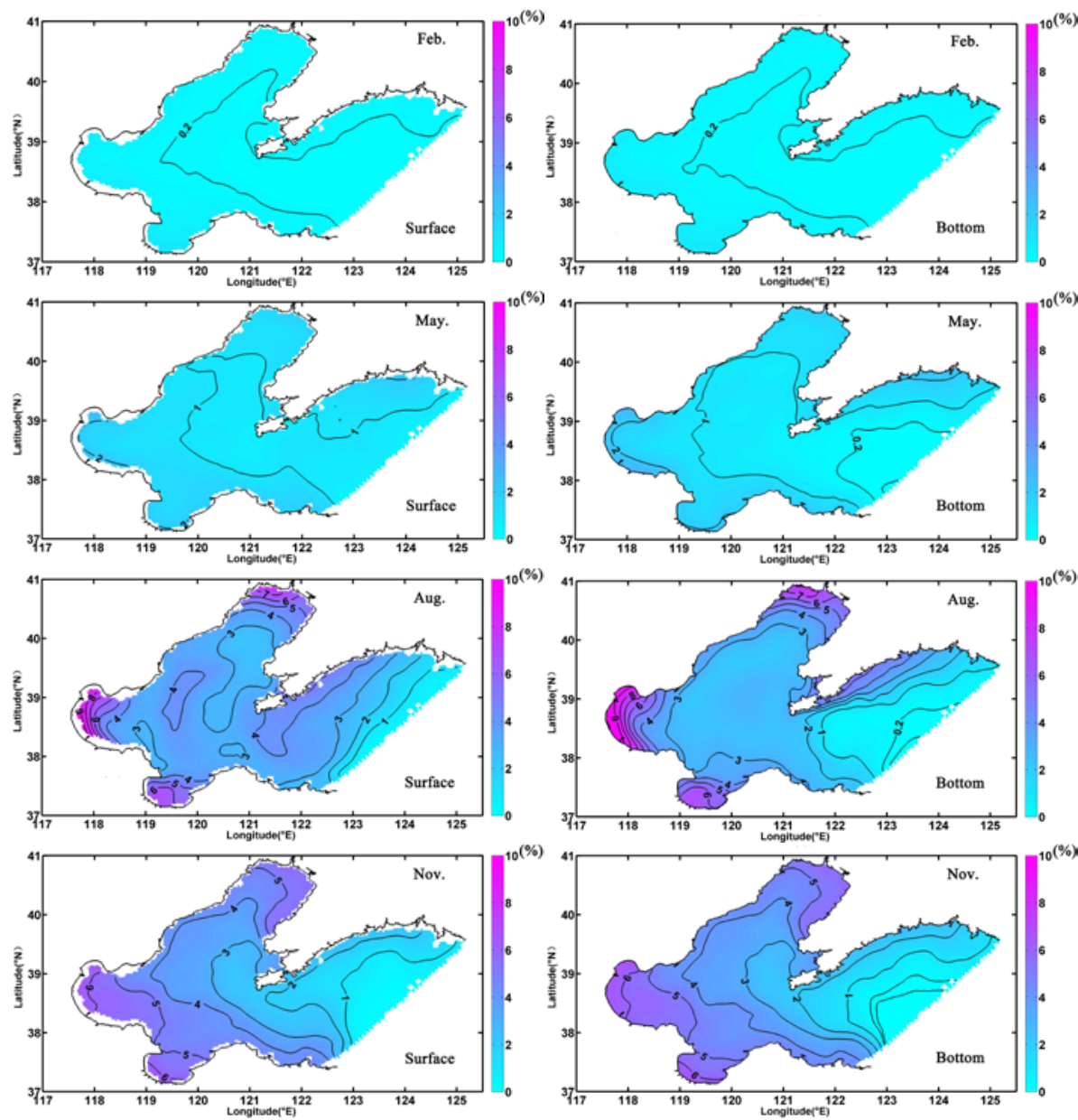

Figure 9 Salinity Variance Ratio at the Surface and Bottom Layers of Bohai Sea in the 4

Representative Months between Experiment 1 and the Reference Experiment

\section{Conclusions and Prospects}

In this article, analysis was made to the seasonal variation characteristics of salinity at Bohai Sea based on FVCOM high resolution model. Seen from the high surface, the salinity of Bohai Sea presents the characteristics of being high at the east and central but low at the north, west and south coasts; meanwhile, the salinity of Bohai Sea was rather large in winter, and decreased gradually from spring to summer, and the salinity increased gradually in fall, and gradually resumed to the level of winter. Affected by the Yellow River runoff, the year-round salinity of Laizhou Bay was the minimum in Bohai Sea, and the level gradient was rather large. Seen from the cross section, the 
seasonal variance characteristics of salinity were similar to that of the high surface, and the development of thermocline can be seen from May to Aug. What was studied respectively in this article is the impact of the Yellow River runoff and precipitation on the salinity at Bohai Sea through two sensitivity experiments. The impact of the Yellow River runoff was mainly reflected in summer and fall, and the affected range concentrated nearby Laizhou Bay, and caused the maximum variance ratio of salinity to be $20 \%$. The impact of the precipitation was also mainly reflected in summer and fall, affected the whole Bohai Sea, caused the variance ratio of salinity to reach the peak of the year in summer, and the maximum variance ratio of salinity was $9 \%, 7 \%$ and $6 \%$ respectively at Bohai Bay, Liaodong Bay and Laizhou Bay.

\section{Acknowledgment}

This paper is supported by Tianjin Natural Science Foundation Project (14JCYBJC22500).

\section{Reference}

[1] D.X. Wu, L.M, Q. Li, X.W. Bao, X.Q. Wan, Long-term variation characteristics of the salinity of the Bohai Sea and the probable leading factors. Progress in Natural Science.,14(2004),191-195(in Chinese).

[2] D.X. Wu, X.P. Lin, X.W. Bao, New Issues in the Dynamic and Environment Studies of the Bohai Sea. Periodical of Ocean University of China.,34(2004),685-688(in Chinese).

[3] S.Z. Feng, F.Q. Li, S.J. Li, Introduction to Marine Science. Higher Education Press(in Chinese),(1999).

[4] J.L. Xu, 2007a. The Variation Characters and Formation Mechanism of Salinity in the Bohai Sea. Ocean University ofChina,2007.

[5] P. Zhao, W.S. Jiang, X.Y. Mao, Salinity Change and Influencing Factor in the Laizhou Bay From 2000 to 2005. Oceanologia Et Limnologia Sinica.,41(2007), 12-23(in Chinese).

[6] X.Y. Mao, W.S. Jiang, P. Zhao, H.W. Gao, A 3-D numerical study of salinity variations in the Bohai Sea during the recent years. Continental Shelf Research.,28(2008),2689-2699.

[7] D. Hainbucher, H. Wei, T. Pohlmann, S. Jurgen, S.Z. Feng, Variability of the Bohai Sea circulation based on model calculations. Journal of Marine System.,44(2004),153-174.

[8] B. H. Choi, K.O. Kim, H.M. Eum., Digital bathymetric andtopographic data for neighborin g seas of Korea (in Korean). KoreanSoc. Coast. Ocean Eng.,14(2002), 41-50.

[9] D.X. Wu, S.H. Gao, Y.M. Wang, X.E. Chen, Monthly Mean Wind and Temperature Atlas of Bohai Sea, Yellow Sea, East China Sea(1960-2007). China Ocean University Press, (2011),150pp(in Chinese).

[10] H. Wei, C.Y. Yuan, Y. Y. Lu, Forcing mechanisms of heat content variations in the Yellow Sea. Journal of Geophysical Research.,118(2013), 4504-4513.

[11] S.B. Dai, S.L. Yang, A. Gao, Z. Liu, P. Li, M. Li, Trend of Sediment Flux of Main Rivers in China in the Past 50Years. Journal of Sediment Research,2(2007),49-58(in Chinese).

[12] China River Sediment Bulletin. China Water \& Power Press(in Chinese)(2003). 